\title{
Otonom Tabanı İşaret ve Şerit Tanımak Amacı ile Bir Öğrenme Sisteminin Geliştirilmesi
}

\section{An Autonomous-Based Learning System Development for Sign and Lane Recognition}

\author{
Ömer Küçük ${ }^{1}$ iD , Emrehan Yavşan 1* iD, Barış Gökçe ${ }^{1}$ iD \\ ${ }^{I}$ Necmettin Erbakan Üniversitesi Mühendislik Fakültesi Mekatronik Mühendisliği Bölümü, 42090, Konya, TÜRKIYYE
}

Başvuru/Received: 07/10/2021

Kabul / Accepted: 25/12/2021

Çevrimiçi Basım / Published Online: 31/12/2021

Son Versiyon/Final Version: 31/12/2021

\section{Öz}

Günlük hayatta trafik kazaları oranlarına bakıldığında sürücü hatalarının oldukça fazla olduğu görülmektedir. Pazara yeni çıkan araç modelleri sürücüye şerit takibi başta olmak üzere akıllı sürüş ve sürüş asistanı gibi otonom veya yarı otonom sürüş destekleri sunan kontrol yöntemleri ile ortaya çıkmaktadır. Bu çalışmada otonom araçların trafikte iken sürücüye yardımcı olması için trafik işaretlerinin doğru olarak tanınması ve sürücüye uyarıda bulunması adına bir sistemin geliştirilmesi amaçlanmıştır. Sistemin geliştirilmesi sürecinde şahsi araç üzerine montajlanmış bir kameradan alınan yol görüntü videolarıyla özgün bir veri seti oluşturulmuş ve bu verilerle trafikte yollarda bulunan işaretlerin ve trafik lambalarının tanınması sağlanmıştır. Yüksek tanıma doğruluğu için çeşitli yapay zeka algoritmaları birleştirilerek etkili bir sınıflandırma gerçekleştirilmiştir. Eğitim veri setinin oluşturulması için şahsi aracın ön camına yerleştirilmiş olan bir yol kamerası ile Konya ili Selçuklu ve Meram ilçelerinin yollarındaki trafik lambalarından ve trafik levhalarındaki işaretlerden video kamera verileri ede edilmiştir. Şahsi araçtan elde edilen veri seti kullanılarak bir yapay sinir ağı modeli eğitilmiştir. Deneysel olarak yapılan bu çalışmada $\% 90$ oranında doğruluk elde edilmiştir. Trafik işaret ve lambalarını tanıma sisteminden sonra otonom bir araç platformu için şerit tanıma ve viraj algılama sistemi geliştirilmiştir. Bu sistem sayesinde aracın direksiyon açısı hesaplanmış ve bir PID kontrolcüyle aracın direksiyonu otonom olarak kontrol edilmiştir.

\section{Anahtar Kelimeler}

"Otonom Sistemler, Yapay Zeka, Gömülü Sistem, İsaret Tanıma"

\begin{abstract}
When we look at the rates of traffic accidents in daily life, it is seen that driver errors are quite high. Newly launched vehicle models come to the market with control methods such as lane tracking, autonomous or semi-autonomous driving support, especially intelligent driving and driving assistant. In this study, it is aimed to develop a system for the correct recognition of traffic signs and warning the driver in order to assist the driver while autonomous vehicles are in traffic. In this study; Recognition and classification of the signs and traffic lights on the roads were made by using the image processing methods of the road image videos taken from a camera mounted on a personal vehicle, and the appropriate classification technique was determined by using different artificial intelligence methods. In this context, a training data set was created to create an artificial neural network (ANN) model and to develop it for this structure. In order to create the training data set, video camera data were obtained from the traffic lights on the roads of Selçuklu and Meram districts in Konya and from the signs on the traffic signs with a road camera placed on the windshield of the personal vehicle. An ANN training was conducted using the data set obtained from the personal tool. In this experimental study, the accuracy rate of $90 \%$ was achieved. After the traffic signs and lights recognition system, a lane recognition and a road curve calculation system has been developed for an autonomous vehicle platform. Thus, the steering angle of the vehicle was calculated and it was controlled autonomously with a PID controller.
\end{abstract}

Key Words

"Autonomous Systems, Artificial Intelligence, Embedded System, Sign Recognition" 


\section{Giriş}

Makineler için atfedilen yapay zeka kavramı insan zekası temel alınarak oluşturulmuştur. Ancak sonraki zamanlarda gelişmiş bilgisayarların ve uzman sistemlerin yazılımsal olarak kullanımının artması ve yaygınlaşması ile yapay zeka hem kavramsal olarak hem de uygulama olarak karşımıza çıkmaktadır. IBM, Apple, Microsoft ve Xerox gibi büyük bilgisayar ve sistem üreticileri yapay zeka ile ortaya çıan, unsuru çok geniş bir alanda olmasa da kendi içlerinde araştırma çalışması olarak devam ettirmişlerdir. Günümüzde bu çalışmalar giderek yaygınlaşmış ve artık günlük hayatın bir parçası olmaya başlamıştır. Bu konuda Turing Testi gibi yarışmalar düzenlenmekte ve yeni nesli bu alana yönlendirmektedir. Turing testinde birbiri ile henüz tanışmayan insanlardan oluşan denekler kendi aralarında ve yapay zeka temelli bir konuşma-diyalog sistemiyle konuşmaktadırlar. Konuşma sonunda denek gruplar üzerinde oluşturdukları konuşmaların hangilerinin insan hangilerinin makine zekası olduğu sorulduğunda makine zekasının insan zekası olduğu zannedilmiş̧ir. Bunun yanında insan zekasının ise makine zekası olduğu zannedilmiştir.

$\mathrm{Bu}$ çalışmada öncelikle bilgisayarlı görme teknikleri kullanılarak yol üzerindeki trafik işaretlerinin ve lambalarının tanınması ve sınıflandırılması, ardından şerit tanıma ve viraj algılama çalışmaları yapılmıştır. Her iki çalışma için de iki ayrı sistem geliştirilmiştir. $\mathrm{Bu}$ sistemler otonom bir araç platformu için yapılmış olup birbirlerinden bağımsız olarak geliştirilmiştir.

\subsection{Yapay Sinir Ağları}

Şekil 1'de biyolojik bir nöron temel alınarak bu nöronun matematiksel uyarlaması gösterilmektedir. Nöron uçlarındaki dendritler uyartım sinyallerini toplar ve sonuç olarak bir çıktı üretirler. Üretilen çıktı aksonlar aracılı̆̆ ile sinapslara taşınır ve sistemdeki diğer nöronlar ile haberleşilir. Buradan hareketle sistemin matematiksel modeli oluşturulmuştur. Yapay nöronda diğer nöronlardan gelen giriş verileri w0, w1 ve w2 ağırlıklarıyla çarpıldıktan sonra toplanır ve bir aktivasyon fonksiyonundan geçirilir. Aktivasyon fonksiyonundan sonra bir çıktı üretilir (Yavsan ve Ucar, 2015).
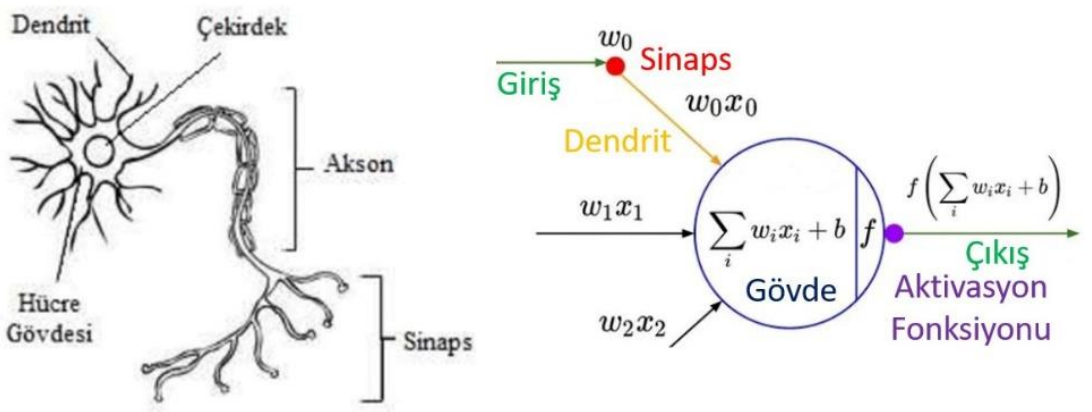

Şekil 1. Temel bir yapay sinir ağının gerçek ve matematiksel modeli

\subsection{Evrişimsel/Konvolüsyon Sinir Ağları}

Evrişimsel, bir diğer ifade ile konvolüsyon sinir ağı dijital bir resim veya görüntü üzerindeki farklı nesneleri tespit edebilen ve sınıflandırabilen bir derin öğrenme algoritmasıdır. Burada temel olan; resim üzerindeki nesnelerin algılanması, sinıflandırılması ve benzerliklerin kümelenmesidir. Şekil 2'de evrişimsel veya konvolüsyon sinir ağı modeli verilmiştir.

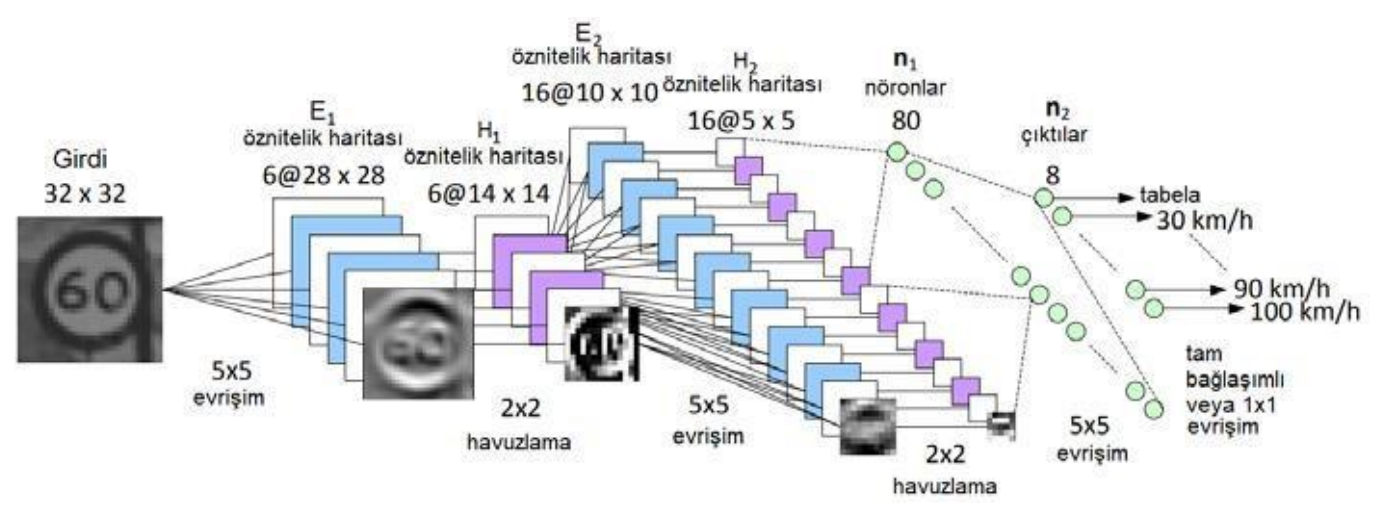

Şekil 2. Evrişimsel/Konvolüsyon sinir ağları modeli (NVIDIA, 2021) 
Bir video görüntüsündeki nesne veya nesnelerin tanınması; sınıflandırma ve nesnenin konumunun belirlenmesi gibi pek çok işlemi içermektedir. Bu çalışmada trafik işaretlerinin ve lambalarının tanınması için Faster R-CNN yöntemi kullanılmış ve derin yapay sinir ağları ile gömülü Linux işletim sistemi üzerinde gerçek zamanlı nesne tanımlama yapılmıştır.

Bir görüntü üzerindeki nesnenin bulunduğu bölge için bölge bazlı evrişimli/konvolüsyon sinir ağı (CNN), gömülü Linux üzerinde GPU kullanarak CPU'lara göre daha hızlı hesaplama işlemi yaparak daha hızlı video işleme ve analiz yapabilmektedir. Bu hesaplamalarda ortalama hassasiyetin (mAP) videodaki görüntülerin sayısına ve resimlerdeki ışıklandırma karakteristiğine bağlı olduğu görülmüştür. Önceki çalışmalarda havanın güneşli, parlak ve kapalı olması arasında farkların olduğu görülmüştür (Simonyan ve Zisserman, 2015).

Evrişimsel bir diğer ifade ile konvolüsyon ağları, nesnelerin görsel olarak tanınma doğruluğunu artırmaktadır. Bunun yanında OverFeat (Sermanet ve diğerleri, 2014); nesnenin tanınması, sınıflandırılması ve konumlandırılması için sistem piramidinden oluşan konvolüsyon özelliklerini hesaplar. Bu çalışmada Faster R-CNN kullanılarak trafik işaretlerinin ve levhalarının daha doğru ve hızlı tanınması sağlanmıştır. Şekil 3’te Faster R-CNN ile sınıflandırma işlemi gösterilmektedir (Girshick, 2015).

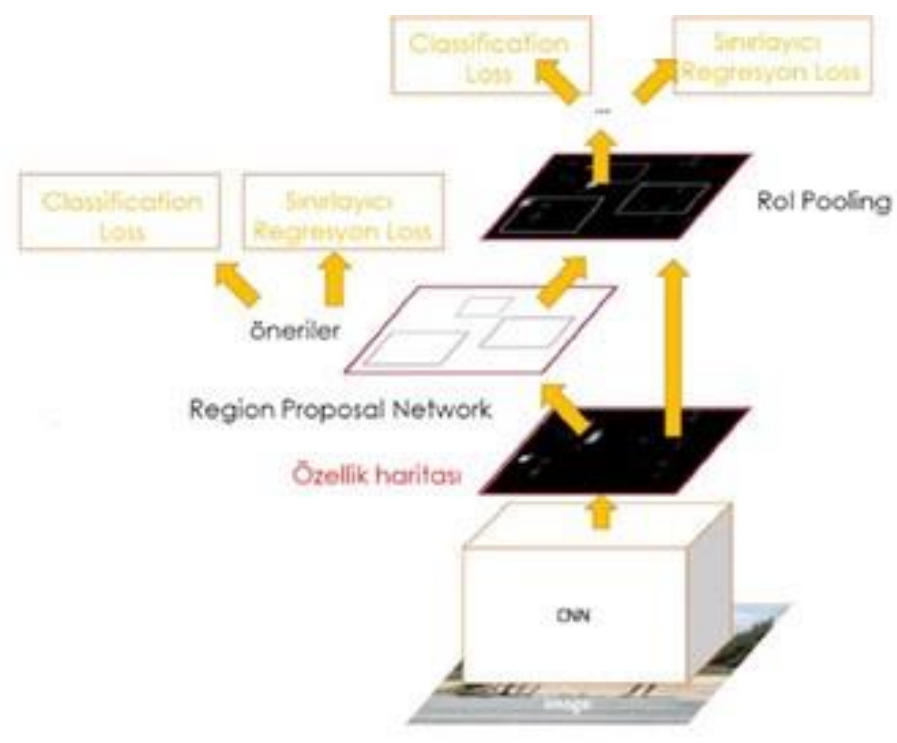

Şekil 3. Faster R-CNN, ile nesnenin sınıflandırılması (Girshick, 2015)

\section{Sistemin Genel Yapısı}

Bu çalışmada gömülü Jetson Nano TX kontrol kartı üzerine gömülü Linux işletim sistemi kurulmuştur. Gömülü Linux üzerinde veri toplama ve anlık görüntü işleme yapılmıştır. Öncelikli olarak şahsi arabanın ön camına geniş açılı bir kamera yerleştirilmiş ve Konya ili içerinde seyahat edilerek yollardaki işaret ve levhalardan bilgi alma işlemleri gerçekleştirilmiştir. Çekilen video görüntülerinde durak, girişi olmayan yol, sağa mecburi yön, park yasak, azami hız sınırı 20, ileri, azami hız sınırı 30 ve dur gibi trafik uyarı işaretleri ile trafik lambalarının belirlenmesi sağlanmışıı. Trafik veri setinin oluşturulması için elde edilen videolardan 14780 adet resim kullanılmış ve 15 farklı sınıflandırma yapılmıştır. Her bir sınıflandırma için 1000 adet resim kullanılmıştır. Makine öğrenmesi (ML) kullanılarak görüntülerin seçilmesi ve eğitilmesi sağlanmıştır (Binangkit ve Widyantoro, 2017).

Çekilen videodan alınan görüntülerdeki nesnelerin tanınması ve sınıflandırılması için video kareleri ayrı ayrı işlenmiş ve her birinin öznitelikleri çıkartılmıştır. Trafik lambalarının ve işaretlerinin algılanmasında sadece renkler ve dik açıdan bakış yeterli değildir. Bununla birlikte açısal bakış veya duruş ile güneşin karşıdan ve yanlardan gelmesi algılamayı olumsuz etkilemekte ve tanımlama oranını azaltmaktadır. Bu açıdan sadece standart renk bazlı öznitelik çıkarma yeterli olmayacaktır. Çözümün geliştirilmesi için birden fazla görüntü segmentasyon yöntemi kullanılmaktadır (Lasota ve Skoczylas, 2016). Araç hareket ederken trafik lambalarının temelde boyutları, rengi ve açısı değişmekte işaret ve levhalar yanlış anlaşılabilecek nesnelere dönüşebilmektedir. Bu sebeple nesnenin doğru algılanması ve sınıflandırılması çok önemlidir. 
Şekil 4. Etiketlenen nesnelerin özelliklerinin tutulduğu csv dosyasının örneği

Etiketleme işlemlerinden sonra .xml olarak kaydedilmiş olan görüntü özelliklerini, TFRecord oluşturmak için .csv dosyasına çevrilmesi gerekmektedir. Dönüşüm uygulandıktan sonra model eğitiminde kullanılacak olan TFRecord dosyası oluşturulmaktadır.

\subsection{Veri Setinin Oluşturulaması ve Sınıflandırılma İşlemi}

Trafik işaretlerinin ve trafik ışıklarının yerleştirildiği farklı ortamlar nedeniyle, yalnızca renk özelliğine dayalı tanıma, ağaçların varlığından veya insanların ürettiği gürültülerden dolayı ilgilenilen bölgelerin sınıflandırılmasını yapmak için yeterli değildir. Bundan dolayı renge dayalı tanıma yerine özellik haritasına dayalı Faster R-CNN algoritmasıyla tanıma gerçekleştirilmiştir. Faster R-CNN kullanarak derin sinir ağları sayesinde gerçek zamanlı nesne tanımaya yaklaşılmıştır (Ren, He, Girshick ve Sun, 2015).

Sunulan çalışma iki aşamadan oluşmaktadır. İlk aşama veri setinin hazırlanmasıdır. İkinci aşama ise eğitim işlemidir. Veri setini oluşturmak için Konya trafiğinde bulunan 1şıklar ve tabelalardan elde edilen fotoğraflar ve videolar kare kare resimlere dönüştürülüp depolanmıştır. Veri seti, farklı hava koşulları ve arka planlarda çeşitlendirilerek YSA modelinin doğruluk oranı arttırılmıştır. Veri setindeki trafik işaretleri ve ışıkları, açık kaynak kodlu LabelImg programıyla etiketlenmiştir. Etiketlenen görüntüler .xml uzantısında bir dosya olarak kaydedilmektedir. Bu .xml dosyası içerisinde Şekil 4 üzerinde gösterildiği gibi görüntünün bulunduğu dosya ismi, görüntünün ismi, dosya konumu, görüntünün boyutları, class ismi olarak tanımlanan nesne ismi ve görüntü üzerinde etiketlenen nesnenin çerçeve değerlerinin bulunduğu bazı özellikler tutulmaktadır.

Tablo 1. Trafik işaretlerini tanıma doğruluk oranları

\begin{tabular}{lcc}
\hline Trafik İşaretleri & Programdaki Kısaltma & Tanıma Oranı (\%) \\
\hline Kırmızı Işı & red & 80 \\
Yeşil Işı & green & 92 \\
Dur & stop & 98 \\
Durak & station & 54 \\
Park Yapmak Yasak & nopark & 74 \\
Girişi Olmayan Yol & close & 76 \\
İleri veya Sola Mecburi Yön & fol & 96 \\
İleri veya Sağa Mecburi Yön & for & 96 \\
Azami Hız Sinırı (30) & thirty & 87 \\
Azami Hız Sınırı (20) & twenty & 89 \\
Sola Dönüş Yasak & nol & 90 \\
Sağa Dönüş Yasak & nor & 90 \\
Park & park & 85 \\
Sola Mecburi Yön & left & 65 \\
Sağa Mecburi Yön & right & 65 \\
\hline
\end{tabular}

Eğitim işlemi için Faster R-CNN inception v2 coco 20180128 modeli kullanılmıştır. Eğitim, 32GB Ram'li 8GB hafızalı NVIDIA QUADRO K5200 GPU ve 40 çekirdeğe sahip CPU'lu bir sunucuda 506.000 iterasyonda ve 3 gün süre ile gerçekleştirilmiştir. Buradaki eğitilen model Nvidia Nano ve NVIDIA GeForce GTX 960M olan bir dizüstü bilgisayarda denenmiştir. Tablo 1'de geliştirilen modelin tanıma doğrulukları verilmiş̧ir. Şekil 5'te ise geliştirilen model ile başarılı bir şekilde tanınan trafik işaret ve lambaları gösterilmektedir. 


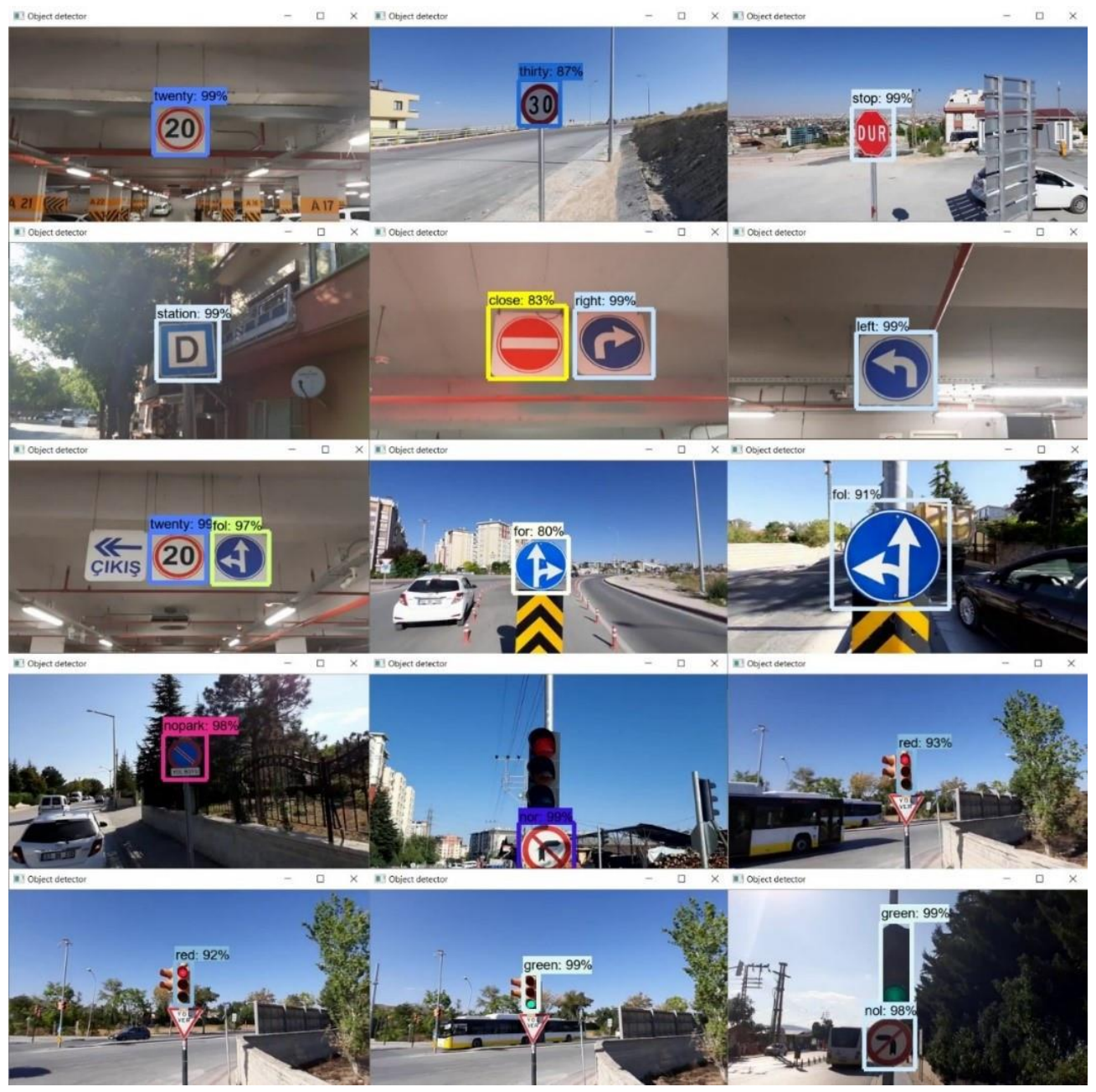

Şekil 5. Geliştirilen tanıma sistemiyle başarılı bir şekilde algılanan trafik işaretleri ve lambaları

\section{2. Şerit Tanıma ve Viraj Algılama Sistemi}

$\mathrm{Bu}$ çalı̧̧mada trafik işaretçilerini tanıma sisteminin yanında Şekil 6'daki otonom araç platformu için şerit tanıma ve viraj algılama sistemi geliştirilmiştir. Yol sınırları veya şeritler, görüntü işleme teknikleri kullanılarak tanınmışıtır. Sistemin geliştirilmesinde aynı trafik işaretçilerini tanıma sisteminde olduğu gibi yine şahsi araca monte edilen bir adet Jetson Nano geliştirme kartı ve bir adet kamera kullanılmıştır. Sistemin işleyişinde ilk olarak kameranın kalibrasyonu yapılıı̧ ve ardından kamera üzerinden alınan görsel/ham veri düzeltilmiștir. Görseldeki gereksiz bilgileri kaldırmak için renk dönüșümleri ve sobel algoritması uygulanmıștır. Perspektif dönüşümle görselin kuşbakışı görüntüsü elde edilmiştir. Maskelemeyle yol sınırları veya şerit pikselleri belirlenip her şerit için en uygun eğriler oluşturulduktan sonra bu eğriler orijinal görsele aktarılmıştır. Bu sayede şerit tanıma işlemi gerçekleştirilmiştir. Tanınan şeritler üzerinden viraj açısı hesaplanmıştır.

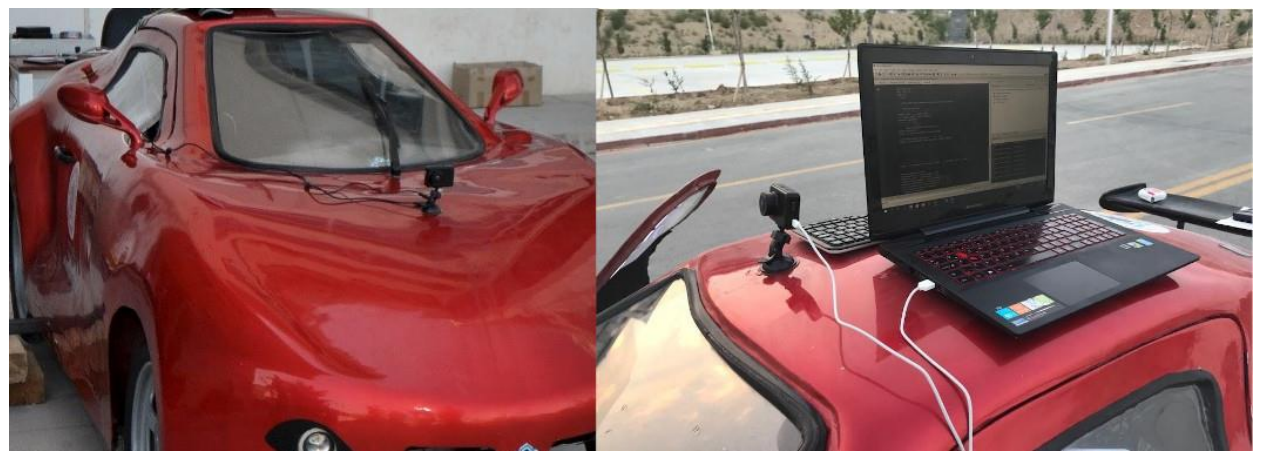

Şekil 6. Şerit tanıma sisteminin kullanılacağı otonom araç 
Şekil 7'de, geliştirilen şerit tanıma ve viraj algılama sisteminin test edildiği arayüz görülmektedir. Burada kameradan alınan görsel üzerinden üç şeritli yolun orta şeridi eş zamanlı olarak tanınmaktadır. Görseldeki kırmızı ve mavi çizgiler; orta şeridin sınırlarını, beyaz çizgi ise bu çizgilerden elde edilen ve viraj açısının hesaplanmasında kullanılan çizgiyi göstermektedir. Bu test görselinden gün ışığı yetersiz olmasına rağmen başarılı bir şerit tanımanın ve viraj algılamanın yapıldığı görülmektedir.

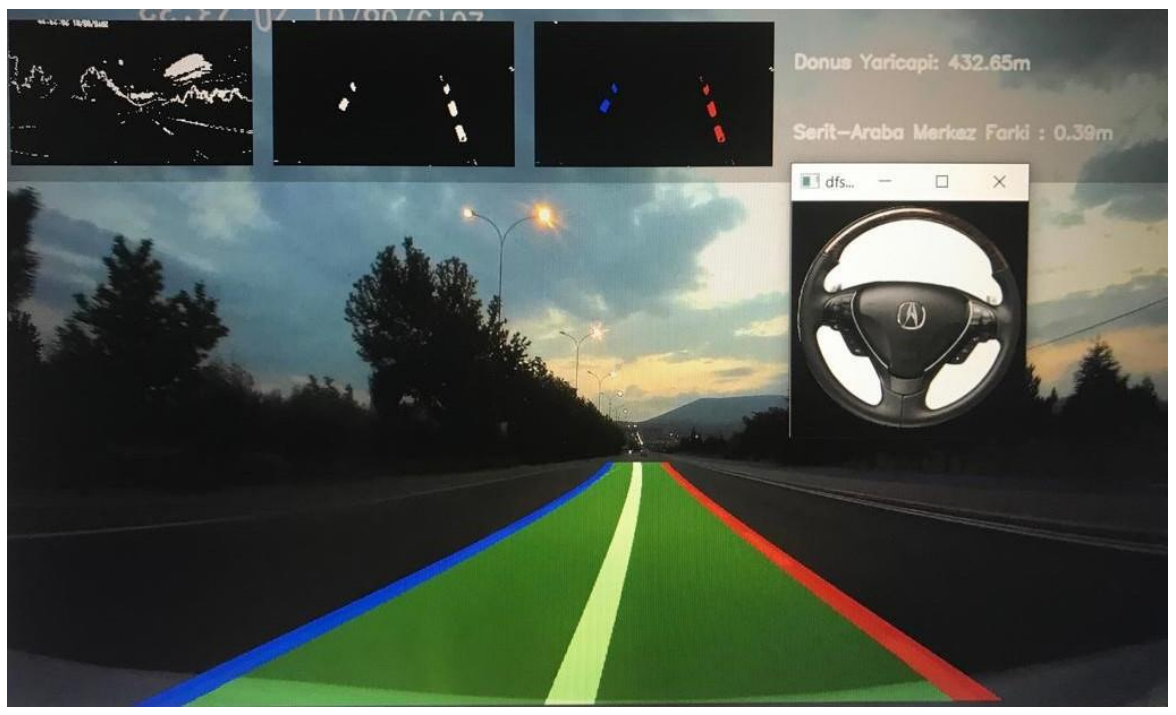

Şekil 7. Şerit tanıma sisteminin testi

Otonom bir sürüş için viraj açısının ilgili aracın direksiyonuna iletilmesi gerekir. Fakat viraj açısı doğrudan aracın direksiyonuna iletilemez. Bu nedenle viraj açısı şekil 6'daki aracın mekaniğine özel çeşitli formülasyonlarla direksiyon açısına dönüştürülmüştür. Direksiyon açısı, otonom sürüş için geri beslemeli kapalı çevrim kontrol sisteminin referansıdır. Böylece Şekil 6' daki aracın direksiyon hareketi, geliştirilen sistem üzerinden hesaplanan viraj açısının çeşitli formülasyonlarla direksiyon açısına dönüştürülmesi ve bu açının kapalı çevrim bir PID kontrolcüye referans girişi olarak verilmesiyle otonom olarak sağlanmıştır.

\section{Sonuçlar}

Akıllı otonom araçların trafikte güvenli bir şekilde seyredebilmesi için trafik işaretçilerinin yüksek doğrulukta tanınması gerekmektedir. Çeşitli algoritmaların birleştirilmesiyle tanıma doğruluğu artırılabilir. Bu çalışmada ilk olarak akıllı bir otonom araçta kullanılmak üzere Faster R-CNN tabanlı bir YSA modeli geliştirilerek trafik ışıkları ve levhaları etkili bir şekilde tanınmıştır. Ağın eğitimi ve testi için 14780 adet görüntü içeren özgün bir veri kümesi oluşturulmuştur. Görüntüler Konya ili içerisinden şahsi araca monte edilen kamerayla toplanmıştır. Video işleme gücünü arttırmak için 15 fps hızında GPU kullanılmıştır. Veri kümesi; dur, durak, park, park yasak, sola dönüş yasak, sağa dönüş yasak, girişi olmayan yol, ileri veya sola mecburi yön, ileri veya sağa mecburi yön, sola mecburi yön, sağa mecburi yön, azami hız sınırı "20", azami hız sınırı "30" trafik işaretleri ve trafik ışı̆ıını iki sınıfta inceleyen kırmızı ve yeşil ışık görüntüleri olmak üzere 15 sınıfta toplanmıştır. Veri kümesinin özellik haritası oluşturulduktan sonra ağ eğitilmiş ve \%90'a varan doğruluk elde edilmiştir. İkinci olarak yine aynı otonom araç için şerit tanıma ve viraj algılama sistemi geliştirilmiştir. Bu sistemle araca monte edilen kameradan alınan görsellerle eş zamanlı olarak viraj açısı hesaplanmaktadır. Hesaplanan viraj açısı, aracın direksiyon açısına dönüştürülerek PID kontrolcü üzerinden aracın otonom sürüşü sağlanmıştır.

\section{Referanslar}

Binangkit, J. L. ve Widyantoro, D. H. (2017). Increasing accuracy of traffic light color detection and recognition using machine learning. Proceeding of 2016 10th International Conference on Telecommunication Systems Services and Applications, TSSA 2016: Special Issue in Radar Technology içinde . doi:10.1109/TSSA.2016.7871074

Girshick, R. (2015). Fast R-CNN. Proceedings of the IEEE International Conference on Computer Vision içinde . doi:10.1109/ICCV.2015.169

Lasota, M. ve Skoczylas, M. (2016). Recognition of multiple traffic signs using keypoints feature detectors. Proceedings of the 2016 International Conference and Exposition on Electrical and Power Engineering, EPE 2016 içinde .

doi:10.1109/ICEPE.2016.7781397 
NVIDIA. (2021). Convolutional Neural Network (CNN). 11 Ağustos 2021 tarihinde https://developer.nvidia.com/discover/convolutional-neural-network adresinden erişildi.

Ren, S., He, K., Girshick, R. ve Sun, J. (2015). Faster R-CNN: Towards real-time object detection with region proposal networks. Advances in Neural Information Processing Systems içinde .

Sermanet, P., Eigen, D., Zhang, X., Mathieu, M., Fergus, R. ve LeCun, Y. (2014). Overfeat: Integrated recognition, localization and detection using convolutional networks. 2nd International Conference on Learning Representations, ICLR 2014 - Conference Track Proceedings içinde .

Simonyan, K. ve Zisserman, A. (2015). Very deep convolutional networks for large-scale image recognition. 3rd International Conference on Learning Representations, ICLR 2015 içinde .

Yavsan, E. ve Ucar, A. (2015). Teaching human gestures to humanoid robots by using Kinect sensor. doi:10.1109/siu.2015.7130053 